\title{
Update on special techniques in routine cytopathology
}

\author{
I D Buley
}

\begin{abstract}
Introduction
Potentially, a vast array of additional techniques may be applied to routine cytopathology (table 1). We have a responsibility to elicit the maximum possible information of diagnostic, therapeutic, and prognostic use from submitted material. Cytological specimens have the intrinsic advantages that they can be obtained safely, rapidly, and inexpensively with minimal trauma to the patient. Advances in imaging by ultrasound scans, computed tomography (CT), and magnetic resonance imaging coupled with accurate stereotactic localisation of lesions have favoured diagnosis by imaging and aspiration cytology or needle biopsy. The development of needles suitable for use with magnetic resonance imaging will increase this trend. Small specimens make the effective use of ancillary techniques all the more crucial. Minimally invasive surgery, which may necessitate the homogenisation of larger resection specimens before removal, and in situ destructive techniques, such as laser, ultrasound scanning, chemical destruction, conventional chemotherapy, and radiotherapy may result in a fall in formal resections of tumours. In future all information may need to be obtained from small specimens. New sources of material and new conditions also mean that we must be alert both to the application of new technology and new uses for well established techniques. This is exemplified by the application of Congo Red staining to fine needle aspiration of abdominal adipose tissue as a novel means of detecting amyloidosis ${ }^{1}$ and recent interest in the use of the Perls stain to detect occult alveolar haemorrhage in HIV positive patients and hence pulmonary Kaposi's sarcoma. ${ }^{2}$ The validation of new techniques must include a pragmatic approach to cost and time effectiveness, and a recognition of the utility of other diagnostic manoeuvres.
\end{abstract}

\section{Table 1 Special techniques applicable to cytopathology}

Histochemistry

Nucleolar organiser region silver staining

Morphometric techniques

Automated cytology

Electron microscopy

Immunocytocher

Flow cytometry

In situ nucleic acid hybridisation and the polymerase chain reaction
The technique of widest applicability, which is well established and widely available, is immunocytochemistry. In spite of the fact that cytologists are often provided with unfixed material with ideal antigenic preservation, the technique is relatively underused. There was initial resistance to the (particularly) indiscriminate use of immunocytochemistry, ${ }^{3}$ but recognition of its scope and limitations in diagnostic cytopathology has established its role. ${ }^{4}$ Standard immunocytochemical techniques can be performed on cytospin preparations, air-dried or wet-fixed "spare" slides, or, in the case of some antigens, can be performed on material already routinely stained and mounted. Cell block material has the advantage that multiple sections can be prepared but suffers the disadvantages of paraffin wax embedded material and limitation of the range of antibodies available. The alkaline phosphatase antialkaline phosphatase technique is particularly recommended for cytological preparations. ${ }^{5}$

\section{Special techniques in effusions}

Distinguishing reactive mesothelial cells, mesothelioma, and metastatic adenocarcinoma in pleural and peritoneal fluids frequently causes a diagnostic problem because morphological and histochemical characterisation may not permit a definitive diagnosis. One third of adenocarcinomas in effusions are periodic acid Schiff diastase negative, and in some series as many as $15 \%$ of effusions have been classified as suspicious, but not diagnostic, of malignancy. ${ }^{6}$ Many antibodies have been suggested as useful, including carcinoembryonic antigen (CEA), ${ }^{7-9}$ Ber-EP4, ${ }^{10}$ CD15, ${ }^{11} 12$ AUA1, ${ }^{13}$ B72 $3,{ }^{11}$ epithelial membrane antigen (EMA), ${ }^{7-9}$ antibodies to secretory component, ${ }^{14} \mathrm{Ca} 2,{ }^{15}$ and antibodies to cytokeratins of different molecular weight. ${ }^{16}$ These antibodies are of varying specificity and sensitivity. The most useful in distinguishing adenocarcinoma from mesothelial cells, either reactive or malignant, are BerEP4, AUA1, and CEA. Ber-EP4 ${ }^{17}$ seems to label all carcinomas, except some hepatocellular carcinomas, but does not seem to react with benign or malignant mesothelial cells. In one series of effusions examined immunocytochemically all 32 cases of adenocarcinoma stained with this antibody and there was no 
staining of mesothelial cells in reactive or mesothelioma effusions. ${ }^{10}$ The antibody AUA1 shows a similar staining pattern to Ber-EP4 with a high degree of sensitivity and specificity. ${ }^{13}$ Antibodies to CEA have been reported to stain up to $80 \%$ of carcinomas in effusions $^{7-9} 18$ and do not show genuine staining of mesothelial cells. False positive staining of granulocytes, macrophages, and mesothelial cells, however, can occur due to non-specific cross-reacting antigens, a family of complex antigens closely related to CEA, ${ }^{19}$ and by non-specific binding to hyaluronic acid in mesotheliomas. Antibodies to CD15 have been reported to stain up to $60 \%$ of carcinomas and only occasionally and weakly stain mesothelial cells. ${ }^{112}$ Epithelial membrane antigen and $\mathrm{Ca} 2$ have each been reported as staining up to $85 \%$ of malignancies, both carcinomas and mesotheliomas, and only stain benign mesothelial cells uncommonly and weakly..$^{7-915}$ They have therefore been advanced as useful in the differential diagnosis between reactive and malignant mesothelial cells. The sensitivity of antibodies to CD15, and the reliability of distinguishing weak from strong staining in the context of routine diagnostic practice with $\mathrm{Ca} 2$ and EMA have been called into doubt in some studies. ${ }^{10}$ Immunocytochemical staining has further roles in effusion cytology with the distinction between benign and malignant lymphoid proliferations and the further characterisation of poorly differentiated malignancies.

Transmission electron microscopy can be an aid to diagnosis in effusion cytology. The detection of intracytoplasmic lumina, well developed intercellular junctions, and junctional complexes characterises adenocarcinomas and mesothelial cells can be distinguished from adenocarcinoma cells by examination of the length to diameter ratio of microvilli. ${ }^{20}{ }^{21}$ These microvilli differences can also be detected by scanning electron microscopy. ${ }^{22}$ Electron microscopy cannot, however, differentiate benign from malignant mesothelial cells; the villous and junctional differences between adenocarcinoma and mesothelial cells are not absolute; and the technique is severely limited where the cells in question are a minority population requiring the examination of many electron microscopic grids.

Special techniques in fine needle aspiration (FNA)

The problem of defining whether a poorly differentiated neoplasm is a carcinoma, melanoma, or lymphoma is common to cytopathology and histopathology. This differential diagnosis particularly arises in fine needle aspirates from lymph nodes. Another diagnostic problem is the distinction of a reactive lymphoid population from a low grade non-Hodgkin's lymphoma. The importance of immunocytochemistry is such that it is essential to have a protocol for lymph node FNA which includes provision for spare
Table 2 Immunocytochemical markers: lymphoma vs carcinoma vs melanoma and lymphoid proliferations

Cytokeratins

Leucocyte common antigen (LCA)

$\mathrm{T}$ and $\mathrm{B}$ cell markers (CD3,CD19, CD22)

$\kappa$ and $\lambda$ light chains

$\kappa$ and $\lambda$ light chains

"Hodgkin's and Reed-Sternberg cell markers" CD15, CD30 S100 and NKI/C3 (melanoma associated antigen ${ }^{23}$ Sanbio)

Table 3 FNA lymph nodes: furthur antibodies for lymphoid lesions

Nuclear proliferation antigen- Ki67

CD5-T cells, centrocytic and lymphocytic non-Hodgkin's lymphomas

CD10-present on some lymphoblastic lymphomas

CD68-macrophage marker

Granulocytic markers - myeloperoxidase, elastase

material. ${ }^{24}$ Ideally a pathologist should perform the aspiration to ensure that appropriate samples are taken and where necessary an aspirate can be taken specifically for immunocytochemical staining. Antibodies can be selected from suitable panels (tables 2 and 3 ). With this kind of approach, accurate diagnoses, with greater than $90 \%$ sensitivity for non-Hodgkin's lymphoma, can be made. This permits follow up and further serological investigation for those with cytologically reactive lymphadenopathy, most of whom will avoid surgery. ${ }^{24}{ }^{25}$ Difficulties remain in the morphological diagnosis of low grade $\mathrm{T}$ cell lymphomas, and immunocytochemical staining may be inconclusive, with the inability to demonstrate monoclonality by light chain restriction.

Electron microscopy permits the detection of melanosomes, intercellular junctions, and intracytoplasmic lumina in FNA of poorly differentiated malignancy. Needle aspiration can provide a fairly pure population of the cell type in question and hence the sampling problems inherent in effusion electron microscopy are less applicable, although heavy blood contamination of samples may necessitate preparation techniques designed to remove red blood cells. ${ }^{26}$

\section{Markers of tumour site and type}

Immunocytochemical staining can indicate the probable primary site or subtype of malignancy. Antibodies of particular use in routine cytological practice are indicated in table 4 .

Table 4 Immunocytochemical markers: tumour site and type indicating markers

UJ13a (anti-NCAM ${ }^{27}$ Dako)-small cell carcinoma Chromogranin, 5HT and specific hormones"neuroendocrine markers"

Thyroglobulin and calcitonin-thyroid tumours Prostatic specific antigen and prostatic acid phosphatase Placental alkaline phosphatase-germ cell tumours AFP-hepatocellular carcinoma and germ cell tumours Human chorionic gonadotrophin germ cell tumours Desmin, factor 8 (\$100, EMA, vimentin, and cytokeratins)sarcomas

Cytokeratins, vimentin, desmin, neurofilaments, neurone specific enolase (NSE), LCA - small round cell tumours of childhood.

GFAP, neurofilaments, NSE, UJ13a, LCA, cytokeratinsCNS tumours

$\mathrm{AFP}=a$ fetoprotein; GFAP $=$ glial fibrillary acidic protein 
The clinical relevance of refining diagnosis by the use of immunocytochemistry is illustrated by the use of prostatic specific antigen in patients who present with cervical lymphadenopathy. This not uncommon situation $^{28}$ is frequently accompanied by the report of a "normal" prostate on examination. Accurate diagnosis will prevent a series of radiological or endoscopic examinations or lymph node biopsy in search of a primary tumour. The recognition of a germ cell tumour is of vital importance because they are readily amenable to treatment by modern chemotherapy. Immunocytochemistry contributes to avoiding the potentially disastrous misdiagnosis of poorly differentiated carcinoma in a computed tomography guided aspirate or needle biopsy from a retroperitoneal lymph node.

One of electron microscopy's strengths is the detection of neurosecretory granules and this technique can be helpful where a "neuroendocrine" tumour is suspected and appropriate material is collected into glutaraldehyde. Theoretically, electron microscopy could be of use in other specific circumstances: for example, the detection of villous core rootlets and glycocalyceal bodies in adenocarcinomas of gastrointestinal origin or intracytoplasmic lamellar bodies and intranuclear tubular inclusions in bronchioloalveolar carcinoma of the lung. The role of this technique is limited, however, and largely superseded by immunocytochemistry. ${ }^{29}$ I would not advocate the routine collection of material for electron microscopy, whereas material for immunocytochemistry is highly desirable. Some ingenious methods for the retrieval of cells for electron microscopic examination from the surface of spare slides have been described. ${ }^{30}$

\section{Detection of additional prognostic or} therapeutic information

The proliferative index in fine needle aspirates can be of prognostic and therapeutic use-for example, as an aid to discerning whether a non-Hodgkin's lymphoma is high or low grade. ${ }^{31}$ The limited sample obtained by FNA, in practice, seems to be representative and as valid an assessment as that obtained by examination of sections of tumour. $^{3132} \mathrm{~S}$ phase assessment has been found to be the most important prognostic factor in node negative carcinoma of the breast and selection of those with a high proliferative index may allow the choice to be made of those who require adjuvent chemotherapy. ${ }^{33}$ Most of the studies involving cytological preparations have used immunostaining with $\mathrm{Ki} 67^{34}$ as a marker of proliferation. Other proliferation related antigens, including proliferating cell nuclear antigen, ${ }^{35}$ are now recognised and require further evaluation. All of these molecules are detectable in phases of the cell cycle other than synthesis and mitosis. A direct measure of $S$ phase can be obtained by the in vivo or in vitro incorporation of bromodeoxyuridine, a thymidine analogue, into tumours and its subsequent detection using a monoclonal antibody. A method applicable to routine fine needle aspiration has been described. ${ }^{36}$ Nucleolar organiser region silver staining, another indicator of proliferation, is readily applicable to cytological material and can be used on previously routinely stained material. ${ }^{37}$ It has not, however, found a niche in routine diagnostic practice.

The presence of hormone and growth factor receptors is similarly of prognostic and therapeutic use, particularly in the context of carcinoma of the breast. These antigens can be detected immunocytochemically ${ }^{38}$ in fine needle aspirate material and this may be necessary in the elderly where treatment with tamoxifen alone, without formal biopsy, may be contemplated.

\section{Special techniques for the detection of infectious agents}

In some circumstances primarily "cytological" material may be used for the diagnosis of infectious disease. Of the traditional stains used for the diagnosis of infectious agents, Ziehl-Neelsen staining of fine needle aspirates from suspected tuberculous lymph nodes is probably the most important, allowing immediate confirmation of the diagnosis of mycobacterial infection in most cases. ${ }^{39}$ Historically, the detection of Pneumocystis carinii in respiratory secretions has fallen within the province of cytopathology. More florid cases of infection can be detected by recognition of the characteristic exudate in routine Papanicolau stained material. ${ }^{40}$ The standard special stain to highlight the cyst walls is a Grocott silver stain. This laborious and time consuming technique has been accelerated by the use of microwaves, ${ }^{41}$ but judgment most be exercised to avoid over or understaining, particularly as cytological control material may not always be available and histological control material is not directly comparable. A simple and rapid toluidine blue technique of similar sensitivity and specificity has been described, ${ }^{42}$ but is not widely used. This also applies to the use of fluorescence microscopy to highlight the bright green fluorescing cyst walls. ${ }^{43}$ Numerous studies have shown that the additional use of monoclonal antibodies to pneumocystis usually linked to a fluorescence marker system increases the sensitivity of detection of this organism. ${ }^{44}$ Antibodies to cytomegalovirus, chlamydia, herpes simplex virus, and human papillomavirus are available and may occasionally be of use in routine practice.

Problems and pitfalls of immunocytochemistry in cytology

There are particular problems associated with this technique in cytology. The first is that of limited quantities of material, and this, together with the probable lack of suitable cytology controls, means that the standard of 
Table 5 Particularly useful antibodies in cytology

Cytokeratin

Leucocyte common antigen

$\kappa$ and $\lambda$ light chains

$B$ and $T$ cell markers

Carcinoembryonic antigen

Ber- EP4

Ber- EP4
S100 and melanoma associ

S100 and melanoma associated antigen (NKI/C3)

Prostatic specific antigen

Thyroglobulin

Calcitonin

technical assistance must be high. Small panels of antibodies should be used to provide internal controls. The high technical standard needed argues for the centralisation of immunocytochemical services where histopathology and cytopathology laboratories are separate, and this is further justified by the necessity of those using the technique to keep abreast of the known specificities of the antibodies used. Other problems encountered include cross-reaction with similar antigens; this is particularly prone to occur with polyclonal antisera, non-specific binding to necrosis or proteins, the presence of endogenous peroxidase or alkaline phosphatase, and diffusion of antigen, particularly prone to occur with thyroglobulin, factor VIII, prostatic acid phosphatase and light chains. It is advisable for those with little experience of the technique to familiarise themselves with the use of a limited range of antibodies (table 5)..${ }^{45}$

\section{Other techniques}

Morphometry has been slow to enter routine practice due to its time consuming nature and a recognition that subjective assessment is as reliable where quantitative measures distinguish clearly and absolutely between different entities. This is in spite of the particular suitability of well spread cytological preparations to this technique. The development of automated image analysis may have some further impact, and there is currently renewed interest in applying this to the screening of cervical smears. ${ }^{47}$ The application of morphometry ${ }^{48-52}$ to fine needle aspiration of the thyroid to distinguish between follicular carcinoma and adenoma has provoked interest as subjective distinction is unreliable. As yet the results have been inconclusive, although some groups have found that morphometric evaluation of nucleoli and nuclear diameter improved discrimination. ${ }^{53}$

Flow cytometry to ascertain ploidy and proliferation is applicable to cytological preparations but has not entered routine practice for reasons of cost and insufficiently large sample size. Its use in effusions is limited by the fact that problem cases are likely to include only a small minority of tumour cells. ${ }^{20}$

DNA technology has a potential interface with routine cytopathology. Its precise role, limitations, and pitfalls have yet to be fully defined. Its possible roles are in the diagnosis of genetic disease, identification of microorganisms, and in tumour pathology.54 Cytology can provide material for traditional Southern blotting techniques, but in situ hybridisation permits preservation of the morphology and direct visualisation of the genetic probe reaction product. The polymerase chain reaction, which allows amplification of selected short segments of nucleic acid, may be particularly applicable to small quantity cytological preparations. ${ }^{55}$ DNA technology for the characterisation of organisms is already beginning to enter routine practice in microbiology laboratories ${ }^{56}$ and diagnosis of pneumocystis, in future, may primarily be made by microbiologists using these techniques. ${ }^{57}$ Genotypic analysis of HPV types has contributed to the understanding of cervical intraepithelial neoplasia (CIN) and carcinoma of the cervix, but as yet no role has been characterised in routine work. ${ }^{58}$ Recombinant DNA technology can be of use in tumour diagnosis. Immunoglobulin gene and $T$ cell receptor gene rearrangement studies can be applied to the cytological diagnosis of $B$ and $T$ cell lymphomas, respectively. ${ }^{59}$ The detection of oncogene mutations may be helpful. Interphase cytogenetics can be carried out by probe detection of specific chromosomal abnormalities in malignancies. This currently limited method ${ }^{60}$ may overcome, to some extent, the drawback of conventional cytogenetics in a routine diagnostic service which is that of speed. Specific cytogenetic aberrations are recognised in lymphoid malignancy, the small round cell tumours of childhood, and in some sarcomas. Efforts are being directed to the detection of consistent chromosomal abnormalities in other solid tumours, ${ }^{61}$ and there is likely to be a defined role for the combination of cytopathology and cytogenetics in the future.

\section{Conclusion}

The selective use of special techniques can transform a tentative diagnosis to a definitive diagnosis hence avoiding further unnecessary investigation; it can refine diagnosis, allowing accurate subtyping of tumours and can obtain additional information of prognostic and therapeutic use.

Advances in imaging, the use of in situ destructive techniques, and the prospect of minimally invasive surgery being used in oncology necessitate the maximum yield of information from cytological specimens, particularly fine needle aspirates. As yet the most important of the special techniques is immunocytochemistry, but in the future the development of sophisticated automated image analysis and the application of nucleic acid technology may have a significant impact.

1 Westermark P, Stenqvist B. A new method for the diagnosis of systemic amyloidosis. Arch Int Med 1973;132 522-3.

2 Hughes-Davis L, Kocjan G, Spittle MF, Miller RF. Occult alveolar haemorrhage in bronchopulmonary Kaposi's sarcoma. F Clin Pathol 1992;45:536-7.

3 Koss LG. The future of cytology. The Wachtel lecture for 1988. Acta Cytol 1990;34:1-9.

4 Wazir JF, Martin-Bates E, Woodward G, Coleman DV Evaluation of immunocytochemical staining as a method of improving diagnostic accuracy in a routine 
cytopathology laboratory. Cytopathology 1991;2:75-82.

5 Cordell J, Falini B, Erber WN, et al. Immunoenzymatic labelling of monoclonal antibodies using immune complexes of alkaline phosphatase and monoclonal antialkaline phosphatase (APAAP) complexes $\mathcal{f}$ Histochem Cytochem 1984;32:219-29.

6 Linari A, Bussolati G. Evaluation of impact of immunocytochemical techniques in cytological diagnosis of neoplastic effusions 7 Clin Pathol 1989;42:1184-9.

7 Al-Nafussi A, Carder PJ. Monoclonal antibodies in the cytodiagnosis of serous effusions. Cytopathology 1990;1: 119-28.

8 Daste G, Serre G, Munduyt M-A, Vincent C, Caveriviere $P$, Soleilhavup J-P. Immunophenotyping of mesothelial cells and carcinoma cells with monoclonal antibodies to cytokeratins, vimentin, CEA and EMA improves the cytodiagnosis of serous effusions Cytopathology 1991;2: 19-28.

9 Marshall RJ, Herbert A, Braye SG, Jones DB. Use of antibodies to carcinoembryonic antigen and human milk fat globule to distinguish carcinoma, mesothelioma, and reactive mesothelium. $\mathcal{F}$ Clin Pathol 1984;37: 1215-21.

10 De Angelis M, Buley ID, Heryet A, Gray W. Immunocytochemical staining of serous effusions with 3:111-7.

11 Warnock ML, Stoloff A, Thor A. Differentiation of adenocarcinoma of the lung from mesothelioma Periodic-Acid Schiff, monoclonal antibodies B72.3 and Leu M1. Am $\mathcal{F}$ Pathol 1988;133:30-8.

12 Tickman RJ, Cohen C, Varma VA, Fekete PS, De Rose PB. Distinction between carcinoma cells and mesothelial cells in serous effusions: usefulness of immunohistochemistry Acta Cytol 1990;34:491-7.

13 Kocjan G, Sweeny E, Miller KD, Bobrow L. AUA1: new immunocytochemical marker for detecting epithelial

14 Kondi-Paphitis A, Addis BJ. Secretory component in pulmonary adenocarcinoma and mesothelioma. Histopathology 1986;10:1279-87.

15 Bramwell ME, Ghosh A, Smith W, Wiseman G, Spriggs A, Harris $\mathrm{H}$. $\mathrm{Ca} 2$ and $\mathrm{Ca} 3$ new monoclonal antibodies evaluated as tumour markers in serous effusions. Cancer 1985;56:105-10.

16 Kahn HJ, Thorner PS, Yeger H, et al. Distinct keratin patterns demonstrated by immunoperoxidase staining of adenocarcinomas, carcinoids and mesotheliomas using polyclonal and monoclonal anti-keratin antibodies. $A m$ polyclonal and monoclonal an

17 Latza U, Niedobitek G, Schwarting R, Nekarda H, Stein H. Ber-EP4: new monoclonal antibody which distinguishes epithelia from mesothelia $f$ Clin Pathol 1990;43: 213-21.

18 Ghosh AK, Spriggs AI, Taylor-Papadimitriou J, Mason DY. Immunocytochemical staining of cells in pleural and peritoneal effusions with a panel of monoclonal antibodies $\mathcal{F}$ Clin Pathol 1983;36:1 154-64.

19 Rogers GT. Carcinoembryonic antigens and related glycoproteins, molecular aspects and specificity. Biochem Biophys Acta 1983;695:227-49.

20 Nance KV, Silverman JF The utility of ancillary techniques in effusion cytology. Diagn Cytopathol 1992;8: $185-9$

21 Bedrossian CWM. Electron microscopy: the neglected tool of cytopathology. Diagn Cytopathol 1992;8:iv-v.

22 Teals TF. Scanning electron microscopy of body fluids. Diagn Cytopathol 1992;8:266-71.

23 Vennegoor C, Calafat J, Hageman PH, et al. Biochemical characterisation and cellular localisation of a formalin resistant melanoma associated antigen reacting with monoclonal antibody NKI/C3. Int $尹$ Cancer $1985 ; 35$ : 287-95.

24 Brown DC, Gatter KC, Mason DY. Immunocytochemical analysis of lymphoid lesions using fine needle aspiration

25 Sneige N, Dekmezian RH, Katz R, et al. Morphologic and immunocytochemical evaluation of 220 fine needle aspirates of malignant lymphoma and lymphoid hyperplasia. Acta Cytol 1990;34:311-22.

26 Akhtar M, Bakry M, Al-Jeaid AS, McClintock JA. Electron microscopy of fine needle aspiration biopsy
specimens: a brief review. Diagn Cytopathol 1992;8: 278-82.

27 Patel K, Rossell RJ, Bourne S, Moore SE, Walsh FS, Kemshead JT. Monoclonal antibody UJ13a recognises the neural cell adhesion molecule (NCAM). Int $f$ Cancer the neural cell ad

28 Jones $\mathrm{H}$ and Anthony PP. Metastatic prostatic carcinoma presenting as left-sided cervical lymphadenopathy: a series of 11 cases. Histopathology 1992;21:149-54.

29 Dar AUH, Hird PM, Wagner BE, Underwood JCE Relative usefulness of electron microscopy and immunocytochemistry in tumour diagnosis: 10 years of retrospective analysis. F Clin Pathol 1992;45:693-6.

30 Hidvegi DF, Gurley AM. Electron microscopy. In; Bibbo $\mathrm{M}$ ed. Comprehensive cytopathology. Philadelphia: WB Saunders, 1991:917-46.

31 Brown DC, Gatter KC, Mason DY. Proliferation in nonHodgkin's lymphoma: a comparison of $\mathrm{Ki}-67$ staining in fine needle aspiration and cryostat sections. $f$ Clin Pathol 1990;43:325-8.

32 Begg AC, Moonen L, Hofland, et al. Human tumour cell kinetics using monoclonal antibodies against idoxuridine: Intratumour sampling variations. Radiother Oncol 1988;11:337-47.

33 Sigurdsson H, Baldetorp B, Borg B, et al. Indicators of prognosis in node-negative breast cancer. $N$ Engl f Med 1990;322:1015-52

34 Brown DC, Gatter KC. Monoclonal antibody Ki67: its use in histopathology. $\mathcal{F}$ Clin Pathol 1990;43:325-8.

35 McCormick D, Hall PA. The complexities of proliferating cell nuclear antigen. Histopathology 1992;21:591-4.

36 Buley ID, Morrison EH, Kaklamanis L, Horak E, Gatte KC. Measuring proliferation in routine fine needle aspirates. Immunocytochemical detection of bromoaspirates. Immunocytochemical detection of bromodeoxyuridine incorporation and Ki67 expr

37 Barsotti P, Ascoli V, Nardi F, Marinozzi V. Silver staining of interphase nucleolar organiser regions in cytologic smears previously stained by the Papanicolau and MayGrunwald-Giemsa techniques. Diagn Cytopathol 1990;6: 289-96.

38 Cuthbert A, Herbert A, Coddington R, Theaker J, Taylor I, Royle GT. Demonstration of oestrogen receptor in symptomatic breast carcinoma, using fine needle aspiration cytology. Cytopathology 1990;1:339-47.

39 Metre MS, Jayaram G. Acid-fast bacilli in aspiration smears from tuberculous lymph node. Acta Cyto smears from

40 Dugan JM, Avitabile AM, Rossman MD, Ernst CS Atkinson BF. Diagnosis of pneumocystis carinii pneumonia by cytologic evaluation of Papanicolau-staine bronchial specimens. Diagn Cytopathol 1988;4:106-11.

41 Loughman NT. Pneumocystis carinii: rapid diagnosis with the microwave oven. Acta Cytol 1989;33:416-7.

42 Paradis IL, Ross C, Dekker A, Dauber J. A comparison of modified methenamine silver and toluidine blue stains for the detection of Pneumocystis carinii in bronchoalveolar lavage specimens from immunosuppressed choalveolar lavage specimens from

43 Wehle K, Blanke M, Koenig G, Pfitzer P. The cytological diagnosis of Pneumocystis carinii by fluorescence microscopy of Papanicolau stained bronchoalveola lavage specimens. Cytopathology 1991;2:113-20.

44 Midgely J, Parsons PA, Shanson DC, Husain OAN, Francis N. Monoclonal immunofluorescence compared with silver stain for investigating Pneumocystis carinil pneumonia. I Clin Pathol 1991;44:75-6.

45 Gatter KC, Mason DY, Heyderman E, et al. Which antibodies for diagnostic cytology? Histopathology 1987;11: $661-4$.

46 Gatter KC, CL Oakley lecture: Diagnostic immunocytochemistry: achievements and challenges. F Pathol 1989 159:183-90.

47 Data on automated cytology systems as submitted by their developers. Anal Quant Cytol Histol 1991;13:300-6.

48 Sprenger E, Lowhagen T, Vogt-Schaden M. Differentia diagnosis between follicular adenoma and follicular carcinoma of the thyroid by nuclear DNA determination. Acta Cytol 1977;21:528-30.

49 Backdahl M, Auer G, Forsslund G, et al. Prognostic value of nuclear DNA content in follicular thyroid tumours. Acta Chir Scand 1986;152:1-7.

50 Luck JB, Mumaw VR, Frable WJ. Fine needle aspiration biopsy of the thyroid. Differential diagnosis by Videoplan image analysis. Acta Cytol 1982;26:793-6.

51 Boon ME, Lowhagen T, Willems J-S. Planimetric studies on fine needle aspirates from follicular adenoma and follicular carcinoma of the thyroid. Acta Cytol 1980;24 145-8.

52 Bondeson L, Bondeson A-G, Lindholm K, Ljungborg O, Tibblin S. Morphometric studies on nuclei in smears of fine needle aspirates from oxyphilic tumours of the thyroid. Acta Cytol 1983;27:437-40.

53 Montironi R, Braccischi A, Scarpelli M, Sisti S, Alberti R. Well differentiated follicular neoplasms of the thyroid: reproducibility and validity of a "decision tree" classifireproducibility and validity of a "decision tree" classifcation based on nucleolar and

54 Arends MJ, Bird CC. Recombinant DNA technology and its diagnostic applications. Histopathology 1992;21 303-13.

55 Greiner TC. Polymerase chain reaction: uses and potential applications in cytology. Diagn Cytopathol 1992;8:61-4.

56 Matthews RC, Burnie JP. Clinical applications of molecular biology to diagnostic microbiology. $f$ Clin Pathol 1992;45:465-7.

57 Wakefield AE, Guiver L, Miller RF, et al. DNA amplification on induced sputum samples for the diagnosis of tion on induced sputum samples for the diagnosis of Pneumocys

58 Byrne MA, Parry GCN, Morse A, Taylor-Robinson D Malcolm ADB, Coleman DV. A prospective study of human papillomavirus infection of the cervix Cytopathology 1990;1:329-37.

59 Davey DD, Kamat D, Zaleski S, Goeken J, Dick FR Analysis of immunoglobulin and $\mathrm{T}$-cell receptor gen rearrangement in cytologic specimens. Acta Cyto 1989;33:583-91.

60 Poddighe PJ, Ramaekers FCS, Hopman AHN. Interphase cytogenetics of tumours. F Pathol 1992;166:215-44.

61 Heim S, Mitelman F. Cytogenetics of solid tumours. In: Anthony PP, MacSween RNM, eds. Recent advances in histopathology 15. Edinburgh: Churchill Livingstone, 1992:37-67. 
Pathology, but as would be expected from the Boston School, Basic Pathology is much stronger on disease mechanisms. On this subject, Underwood's otherwise attractive book is seriously flawed; acute inflammation accompanied by a denial of all knowledge of cytokines and cell adhesion molecules, and scant coverage of shock, contrasts with four pages of up to date coverage in Basic Pathology.

A more worthy competitor is found in the revamped Muir which has benefited from both awareness of advances in cellular and molecular biology, and a noticeable improvement in the typesetting and presentation of the text.

For the student with a liking for smaller books, the current edition of Basic Pathology can be recommended. However, a new edition of Underwood with properly written chapters on the basic mechanisms of disease (of primary importance to the undergraduate student), might well prove to be an overwhelming competitor.

WR ROCHE

Essentials of Cytology. An Atlas. G-K Nguyen, TS Kline. (Pp 251; f90.) Waverly Europe Ltd. 1993. ISBN 0-89640-231-2.

This atlas would be a useful benchbook in any cytology department, as it combines the essentials of both gynaecological and nongynaecological cytology. The layout of each chapter with its tables, lists of pitfalls, illustrations, and suggested reading makes this a handy reference book. It is a great pity that the excellent photomicrographs are in black and white, and not in colour.

$M y$ initial excitement at seeing decidual cells and Arias-Stella cells included under pitfalls in the section on "adenocarcinoma and related lesions of the cervix" gave way to disappointment, as there is no explanation of how these cells may be identified. The examples illustrated are not particularly helpful in this respect. A favourable point is that the various squamous lesions are described using both the Bethesda classification and the terminology used in this country-namely, cervical intraepithelial neoplasia (CIN) and dysplasia.

The chapter on the endometrium fills a noticeable gap in reported cytology as it describes the appearances seen with direct sampling - a technique which is becoming more widely used-and is accompanied by useful illustrations.

A feature that detracts somewhat is that the photomicrographs in the chapters on the "gastrointestinal tract" and "breast" appear to be in no particular order. For example, gastric, colonic, oesophageal, and rectal cytology are intermingled, and benign and malignant breast cases appear in a random manner.

No mention is made of the commoner conditions diagnosable on cerebrospinal fluid examination such as meningitis and multiple sclerosis.

To summarise, this is a very useful book with excellent photomicrographs. Changing to colour photomicrographs would add much to its value as appearances vary considerably between wet fixed, Papanicolaou stained material, and its air dried counterparts. The book is well worth having in a cytology laboratory which processes both cervical and non-gynaecological samples, and will be of help to both medical laboratory scientific officers and trainee pathologists alike.

G MCKEE
Pediatric Dermatology and Dermatopathology. A Text and Atlas. Vol 2. R Caputo, A Bernard Ackerman, EQ SisonTorre. Vol 2. (Pp 505; £167.) 1993. ISBN 0-8121-1414-4.

This is the second of a planned set of four volumes with the same title, the first having been published in 1990 (ISBN 0-8121-1166-4).

Volume 2, like its predecèssor, is a book of great distinction. The text is complemented by well chosen, full colour clinical photographs, which are generous in number and in size of reproduction. Large numbers of full colour photomicrographs accompany outstanding descriptions of the histopathology of the disorders under consideration. These photomicrographs are of peerless quality. The appearance, inside and out, of these books can only be described as sumptuous, and, overall, the result is arguably the most beautiful textbook of dermatology ever produced.

Any criticism of this book must be measured against this background. The conditions described are listed in alphabetic order, so that Volume II covers the ground between "Darier's disease" and "hydroa vacciniforme". This is fine, but since some disorders have different names in different countries, locating the relevant subject can be difficult. Thus what an English reader would call "napkin dermatitis" is listed under " $D$ " for "diaper dermatitis". This difficulty is compounded by the lack of an index in the two volumes published so far, and of course, by the fact that only half of the subject matter has so far been covered. One presumes that an index will appear with the final volume, but life with these books will be less than perfect in the meantime.

These are books for the enthusiast. There are others that more or less cover the same ground and which can be obtained more economically. However, the great beauty of the books and the combination of wonderful illustrations, exceptional histopathological descriptions, and excellent referencing put these works in a class of their own, defying comparison. Anyone deeply interested in paediatric dermatology would wish to own copies if ownership can be afforded, and they should find a place in any self respecting dermatology or pathology library. They are at their very best on those rare occasions when one finds oneself with a little time for browsing.

DJ ATHERTON

\section{Some new titles}

The receipt of books is acknowledged, and this listing must be regarded as sufficient return for the courtesy of the sender. Books that appear to be of particular interest will be reviewed as space permits.

Biocatalyst Design for Stability and Specificity. Ed M E Himmel, G Georgiou. ACS Symposium Series 516. (Pp 335; no price given) American Chemical Society. 1993. ISBN 0-8412-2518-4.

Oxygen Free Radicals in Tissue Damage. Ed M Tarr, F Samson. (Pp 295; 168 sw fr.) Birkhauser. 1993. ISBN 08176-3609-9.

\section{Notices}

\section{Diagnostic Medical Mycology \\ Organised by British Society for Mycopathology \\ Leeds: 11 April to 15 April}

Intended for MLSOs and medical graduates working in diagnostic laboratories.

Course fee (excluding accommodation) $£ 285$ + VAT.

Further details can be obtained from Professor E G V Evans,

PHLS Mycology Reference Laboratory, Department of Microbiology,

University of Leeds, Leeds, LS2 9JT.

\section{Association of Clinical Pathologist Trainee Membership}

Trainee membership of the Association is available to medical practitioners who are in training in pathology. Trainee members are able to remain in this category until they achieve consultant or other career grade status (this includes staff grades). The annual subsicription is $£ 32.50$ for those resident in the United Kingdom and Republic of Ireland and $£ 75$ for those overseas. The annual subscription may be claimed against tax.

Trainee members receive the fournal of Clinical Pathology each month. Other benefits are reduced registration fees to attend ACP scientific meetings, all the documents regularly sent to full members of the Association including $A C P$ News, which has a regular column for trainees, and the twice yearly summary of pathology courses included in the ACP programme of postgraduate education. Trainee members have their own representative body, the Trainee Members' Group, which has a direct input to Council.

For Trainee Membership apply to: The Honorary Secretary, Association of Clinical Pathologists, 221 Preston Road, Brighton BN1 6SA. Tel: (0273) 561188. Fax: 0273541227.

\section{Corrections}

In the final paragraph of the reply to $\mathrm{Dr}$ Benbow's letter on ethics and necropsies $(F$ Clin Pathol 1993;46:973) the reference should be 2 and not 3 .

In the September issue of the journal, a printing error appeared in $\mathrm{Dr}$ Appleton's leading article. Dr Appleton's maiden name is $\mathrm{Dr}$ McCarthy and not $\mathrm{Dr}$ McGrehy, as published. The study referred to in reference 76 was also done under the name of Appleton and not McCarthy.

In the leading article on the update on special techniques in routine cytopathology by Dr Buley (October issue), there is an error in line 23 of the introduction. This refers to ultrasound scanning as an in situ destructive technique; the term scanning was incorrectly inserted during the editorial process. 